\title{
EKSISTENSI MODERASI ISLAM DALAM KURIKULUM PEMBELAJARAN PAI DI SMA
}

\author{
Yunus ${ }^{1}$, Arhanuddin Salim ${ }^{2}$ \\ Nurhang542@gmail.com \\ ${ }^{1}$ STMIK Eresha;
}

\begin{abstract}
Students become very vulnerable groups dragged down by the flow of religious radicalism. The age is still very young and still unstable with a burning spirit, and longing to practice religion more käffah (comprehensive) making young groups including Muslim students in high school will be the most vulnerable social groups infiltrated and targeted by radical groups preach religious understanding and attitudes that are rigid and tend to be superficial. On the other hand, religious liberalism at the same time has also begun to infiltrate some young people, including Muslim students in high school. So it is necessary, a strategy to instill moderate Islamic values into students by utilizing the teaching and learning activities of Islamic Education in the classroom. This is because the main actors who are perpetrators of violence, anarchistic actions in religious conflict with religious backgrounds are groups affiliated to Islam. So that inevitably, Islamic Education has moral and social responsibility to help find a way out.
\end{abstract}

Keywords: Moderation of Islam, Islamic Education, Students.

\begin{abstract}
Abstrak
Siswa menjadi kelompok yang sangat rawan terseret oleh arus radikalisme keagamaan. Usia yang masih sangat muda dan masih labil dengan semangat yang menyala-nyala, serta kerinduan untuk menjalankan agama secara lebih kāffah (komprehensif) membuat kelompok muda termasuk siswa beragama Islam di SMA akan menjadi kelompok sosial yang paling rentan disusupi dan menjadi sasaran dari kelompok radikal yang mendakwahkan pemahaman dan sikap keagamaan yang kaku dan cenderung dangkal. Di sisi lain, liberalisme agama pada saat yang sama juga sudah mulai merasuk ke sebagian kalangan muda, tak terkecuali siswa Muslim yang ada di SMA. Maka perlu, strategi untuk menanamkan nilai-nilai moderat Islam ke dalam diri peserta didik dengan memanfaatkan kegiatan belajar mengajar Pendidikan Agama Islam di kelas. Hal ini karena faktor-faktor utama pelaku kekerasan, tindakan anarkistis dalam konflik social berlatarbelakang agama adalah kelompok-kelompok yang berafiliasi pada Islam. Sehingga mau tidak mau, Pendidikan Islam mempunyai tanggungjawab moral dan social untuk turut mencari jalan keluarnya.
\end{abstract}

Kata Kunci: Moderasi Islam, Pendidikan Agama Islam, Siswa.

\section{PENDAHULUAN}

Islam sebagai agama samawi yang diturunkan Tuhan kepada umat manusia di semesta ini pada prinsipnya mengandung perintah positif. Perintah positif yang ada dalam Islam sudah diyakini lebih dari XV abad yang lalu (Aziz, 2016; Harahap, 1997; Kholil, 1994; Nata, 1996; Shihab, 1996; Sulaiman, 1989). Pada masa itu Allah SWT 
menurunkan seorang Nabi dan Rasul terakhir, Muhammad Ibn 'Abdillâh. Nabi Muhammad SAW pun dalam menyampaikan ayat-ayat kitâbullâh dengan metode atau cara yang rahmat (positif), sebagaimana Allah SWT ketika menyampaikan kalam-Nya di Al-Qur'an. Ayat-ayat dalam Al-Qur'an sendiri, jika diteliti dengan seksama, maka akan didapati ayat-ayat mengandung hal positif. Jika ada ayat-ayat yang 'berbau' negatif pun tidak lain hanyalah larangan (nahî) dari Allah, agar manusia tidak tersesat dari jalan yang lurus.

Kehidupan beragama di Indonesia akhir-akhir ini mendapatkan sorotan dari berbagai pihak, baik dari dalam negeri sendiri, maupun dari luar. Hal ini tak lepas dari terus bermunculannya konflik sosial berlatarbelakang agama di tengah masyarakat. Mulai dari kasus penistaan agama, perusakan rumah ibadah, ujaran kebencian di media sosial dan saling mendiskreditkan antara satu umat dengan umat yang lain. Menjamurnya fenomena-fenomena ini mau tidak mau semakin mempertajam sentimen keagamaan di Indonesia. Sebagai akibatnya, kerukunan dan rasa kekeluargaan sebagai satu bangsa menjadi renggang dan terkotak-kotak berdasarkan agama dan kepercayaan masing-masing. Ironisnya, sebagian besar aktor-aktor konflik tersebut adalah umat Islam. Kenyataan ini tak bisa diabaikan begitu saja, karena menyangkut masa depan nasionalisme dan keutuhan negara. Sebuah ironi, di tengah semakin ketatnya persaingan global, Indonesia justru akhir-akhir ini disibukkan dengan urusan "rumah tangga". Persoalan yang sebenarnya tak perlu diberdebatkan justru menjadi penyita perhatian dan penutup mata terhadap persoalan-persoalan besar yang dihadapi Indonesia ke depan.

Konflik-konflik sosial berlatarbelakang agama sebagaimana disinggung di atas, jika ditelisik sebenarnya berakar dari kegagalan dalam mendialogkan pemahaman agama dengan realitas sosial di Indonesia yang beragam, plural dan multikultural. Hal ini terutama dialami oleh kelompok-kelompok garis keras yang tidak mau mentolelir dan sulit berkompromi dengan pemahaman agama lain yang berbeda. Bagi mereka, beragama yang benar adalah beragama yang seperti mereka lakukan. Sikap dan pemahaman ini didukung dengan realita bahwa Islam menjadi agama mayoritas di Indonesia.

Pendidikan agama yang menekankan pentingnya dialog menjadi kebutuhan utama saat ini. Model pendidikan agama tersebut adalah bagian dari upaya untuk menciptakan harmonisasi dalam hubungan antar agama. Terjadinya berbagai konflik 
yang bernuansa agama, menyebabkan hubungan antar agama saat ini kembali mengalami benturan keras. Berbagai indikator yang memperlihatkan adanya tandatanda perpecahan bangsa dengan transparan mudah disaksikan. Peristiwa tersebut, bukan saja telah banyak merenggut korban jiwa, tetapi juga telah menghancurkan ratusan tempat ibadah (baik masjid maupun gereja) (Achmad, 2001). Kondisi ini adalah suatu ironi terhadap dinamika kerukunan beragama dalam pendulum dunia di abad-21 saat ini. Ironisnya, sikap dan perilaku semacam itu dikembangkan secara sistematis melalui dunia pendidikan, termasuk pendidikan agama, yang cenderung menghasilkan manusia absolut, mutlak-mutlakan (Baidhawy, 2005).

Berdasarkan level sistem pendidikan, semua persoalan yang ada dalam sistem pendidikan di Indonesia ditemukan juga dalam pelaksanaan pendidikan agama di sekolah atau di perguruan tinggi. Meski pendidikan agama tidak masuk mata pelajaran yang diujikan dalam ujian nasional, namun berkaitan dengan administrasi kependidikan, termasuk kurikulum, sampai evaluasi semakin memberatkan pendidikan agama. Belum lagi beban berat pendidikan agama yang menjadi jangkar dalam membangun moral peserta didik (Listia, Arham, \& Gogali, 2007). Pada sisi yang lain, di beberapa sekolah dan perguruan tinggi umum, yang peserta didiknya beragam secara agama. Ketika jam pelajaran agama tiba mereka dipisahkan sesuai dengan agamanya masing-masing. Di kalangan peserta didik sendiri dengan mudah ditemukan bahwa sebenarnya mereka sangat santai dalam menghadapi perbedaan. Tetapi dengan adanya pemisahan ini, seolah-olah menggambarkan dan menanamkan kesadaran kepada peserta didik bahwa agama itu sesuatu yang memisahkan manusia.

Praktik seperti itulah yang berlangsung sejak pendidikan paling dasar, PAUD (Pendidikan Anak Usia Dini), Taman Kanak-kanak (TK), Sekolah Dasar (SD), SMP, SMU hingga perguruan tinggi. Ini belum memasukkan praktik-praktik 'pengajaran' agama yang dijalankan oleh organisasi-organisasi ekstra sekolah seperti 'rohis' (kerohanian Islam) di lingkungan sekolah-sekolah umum dan atau semacam bimbingan 'Studi Agama Islam' di Perguruan Tinggi Umum. Tentu saja memperoleh pendidikan agama yang diyakini itu sangat penting dan juga merupakan hak. Tetapi melulu memperoleh pengajaran agama sendiri, dan mengabaikan serta bahkan menyingkirkan pengetahuan mengenai agama dan kepercayaan orang lain, hanya akan membentuk pribadi-pribadi yang selalu merasa benar sendiri, mudah berprasangka, tertutup, sulit 
bekerjasama dengan orang lain, dan seterusnya. Oleh karena itu, dibutuhkan upaya untuk melakukan pembaharuan dalam bidang pendidikan agama. Pembaharuan secara strategis (konsep dan teknis) harus selalu digaungkan secara terus menerus, mengingat peserta didik adalah manusia yang sangat dinamis dan unik. Ditambah dengan kemajuan teknologi dan informasi yang tidak bisa terelakkan. Maka dibutuhkan konsepsi pendidikan agama yang menjadikan peserta didik berkarakter terbuka, toleran, inklusif, dan pluralis.

Beragam upaya sudah dilakukan untuk meredam permasalahan ini, beberapa di antaranya adalah pemerintah melalui Kementerian Agama menjembatani dialog antar umat beragama, advokasi terhadap umat, aliran dan/atau kelompok-kelompok minoritas korban kekerasan atas nama agama, membekukan ormas-ormas yang kerap berlaku anarkistis dengan mengatasnamakan agama dan yang tidak sejalan dengan semangan kebhinneka-an. Berangkat dari titik inilah, tulisan ini mencoba menawarkan sebuah strategi untuk menanamkan nilai-nilai moderat Islam ke dalam diri siswa dengan memanfaatkan kegiatan belajar mengajar di kelas. Strategi yang ditawarkan adalah dengan melakukan revitalisasi Pendidikan agama di lingkungan Pendidikan Sekolah Menengah Atas (SMA/SMU). Mengapa pendidikan Islam? Hal ini karena faktor-faktor utama pelaku kekerasan, tindakan anarkistis dalam konflik sosial berlatarbelakang agama adalah kelompok-kelompok yang berafiliasi pada Islam.

Berdasarkan penelitian terdahulu, telah dilakukan beberapa penelitian tentang moderasi islam (Abdurrohman, 2017; Suharto, 2017; Yahya, 2018) dan beberapa peneliti membahas tentang pembelajaran PAI di sekolah (Ainiyah, 2013; Anwar, 2016; Arif, 2012; Azizah, Muslihudin, \& Suteja, 2013; Rokhmad, 2012; Wibowo, 2014; Wiyani, 2012) serta di keluarga dan di masyarakat (Hair, 2018; Kholiq, 2015). Namun, belum terdapat penelitian sebelumnya yang membahas tentang moderasi islam dalam pembelajaran PAI. Maka, tujuan penelitain ini adalah mengetahui strategi untuk menanamkan nilai-nilai moderat Islam ke dalam diri peserta didik dengan memanfaatkan kegiatan belajar mengajar pada pembelajaran pendidikan agama islam di kelas.

\section{HASIL KAJIAN DAN PEMBAHASAN}


Pedoman pengembangan standar kompetensi dan kompetensi dasar menjelaskan bahwa mata pelajaran PAI di sekolah memuat materi Al-Qur'an dan Hadis, Akidah, Akhlak, Fikih, dan Tarikh. Ruang lingkup tersebut menggambarkan materi PAI yang mencakup perwujudan keserasian, keselarasan, dan keseimbangan hubungan manusia dengan Allah swt, diri sendiri, sesama manusia, makhluk lainnya, maupun lingkungannya. Pendidikan agama di sekolah bertujuan meningkatkan dan menumbuhkan keimanan melalui pemberian dan pemupukan pengetahuan, penghayatan, pengalaman, serta pengalam peserta didik tentang agama Islam sehingga menjadi manusia muslim yang terus berkembang dalam hal keimanan, ketaqwaannya terhadap Allah swt., serta berakhlak mulia dalam kehidupan pribadi, bermasyarakat, berbangsa dan bernegara dan dapat melanjutkan pada tingkat pendidikan yang lebih tinggi.

Pendidikan agama dimaksudkan untuk peningkatan potensi spiritual dan membentuk peserta didik agar menjadi manusia yang beriman dan bertaqwa kepada Tuhan Yang Maha Esa dan berakhlak mulia. Akhlak mulia mencakup etika, budi pekerti, dan moral sebagai perwujudan dari pendidikan agama. Peningkatan potensi spiritual mencakup pengamalan, pemahaman, dan penanaman nilai-nilai keagamaan, serta pengamalan nilai-nilai tersebut dalam kehidupan individual ataupun kolektif kemasyarakatan. Peningkatan potensi spiritual tersebut pada akhirnya bertujuan pada optimalisasi berbagai potensi yang dimiliki manusia yang aktualisasinya mencerminkan harkat dan martabatnya sebagai makhluk Tuhan. Oleh karena itu, pendidik diharapkan dapat mengembangkan metode pembelajaran sesuai dengan standar kompetensi dan kompetensi dasar. Pencapaian seluruh kompetensi dasar perilaku terpuji dapat dilakukan melalui penanaman nilai, nilai agama. Peran semua unsur sekolah, orang tua peserta didik dan masyarakat sangat penting dalam mendukung keberhasilan pencapaian tujuan PAI.

Adapun tujuan PAI di sekolah sebagai berikut: 
1. Menumbuh kembangkan Akidah melalui pemberian, pemupukan, dan pengembangan pengetahuan, penghayatan, pengamalan, pembiasaan, serta pengalaman peserta didik tentang Agama Islam sehingga menjadi manusia muslim yang terus berkembang keimanan dan ketaqwaannya kepada Allah.

2. Mewujudkan manusia Indonesia yang taat beragama dan berakhlak mulia yaitu manusia yang berpengatahuan, rajin beribadah, cerdas, produktif, jujur, adil, etis, disiplin, toleransi, menjaga keharmonisan secara personal, dan sosial serta mengembangkan budaya agama dalam komunitas sekolah.

Abdul Majid dan Dian Andayani, menjelaskan bahwa materi pendidikan agama Islam berdasarkan rumusan dari pokok ajaran Islam meliputi Akidah (keimanan), syariah (keIslaman) dan akhlak (budi pekerti). Ketiga kelompok ilmu agama itu kemudian dilengkapi dengan pembahasan dasar hukum Islam yaitu Alquran dan Hadis serta ditambah lagi dengan sejarah Islam (tarikh) (Majid, 2004)

Adapun ruang lingkup pelajaran Pendidikan Agama Islam di Sekolah Menengah Atas berfokus pada aspek:

1. Alquran/Hadis.

2. Keimanan.

3. Syariah.

4. Akhlak.

5. Tarikh. 


\begin{tabular}{|c|c|c|c|}
\hline \multicolumn{2}{|c|}{$\begin{array}{c}\text { KOMPETENSI } \\
\text { DASAR }\end{array}$} & \multirow{2}{*}{$\begin{array}{l}\text { MATERI } \\
\text { PEMBELAJARAN } \\
\text { - Q.S. Al-Kafirun } \\
\text { - Q.S. Yunus; 40-41 } \\
\text { - Q.S. Al-Kahfi; } 29\end{array}$} & \multirow{2}{*}{$\begin{array}{l}\text { KEGIATAN PEMBELAJARAN } \\
\text { - Membaca Al-Qur'an surat } \mathrm{Al} \\
\text { Kafirun, Yunus: 40-41 dan } \mathrm{Al} \\
\text { Kahfi : } 29 . \\
\text { - Mengidentifikasi tajwid Q.S. Al } \\
\text { Kafirun, Yunus: 40-41, dan } \mathrm{Al} \\
\text { Kahfi : } 29 .\end{array}$} \\
\hline & $\begin{array}{l}\text { Membaca Q.S. } \\
\text { Al-Kafiruun, } \\
\text { Q.S. Yunus: 40- } \\
\text { 41, dan Q.S. Al- } \\
\text { Kahfi: } 29\end{array}$ & & \\
\hline 1.2 & $\begin{array}{l}\text { Menjelaskan } \\
\text { arti Q.S. Al- } \\
\text { Kafiruun, Q.S. } \\
\text { Yunus: 40-41, } \\
\text { dan Q.S. Al- } \\
\text { Kahfi: } 29\end{array}$ & $\begin{array}{ll}\text { - } & \text { Q.S. Al-Kafirun } \\
\text { - } & \text { Q.S. Yunus; 40-41 } \\
\text { - } & \text { Q.S. Al-Kahfi; } 29\end{array}$ & $\begin{array}{l}\text { - Mengartikan per-kata Al-Qur'an } \\
\text { surat Al Kafirun, Yunus: 40-41 } \\
\text { dan Al Kahfi: } 29 . \\
\text { - Mengartikan per-ayat } \mathrm{Al} \\
\text { Kafirun, Yunus: 40-41, dan Al } \\
\text { Kahfi : } 29 . \\
\text { - Mendiskusikan terjemah Al- } \\
\text { Qur'an surat Al Kafirun, Yunus: } \\
\text { 40-41 dan Al Kahfi: } 29 .\end{array}$ \\
\hline 1. & $\begin{array}{l}\text { Membiasakan } \\
\text { perilaku } \\
\text { bertoleransi } \\
\text { seperti } \\
\text { terkandung } \\
\text { dalam Q.S. Al- } \\
\text { Kafiruun, Q.S. } \\
\text { Yunus: 40-41, } \\
\text { dan Q.S. Al- } \\
\text { Kahfi: } 29\end{array}$ & $\begin{array}{l}\text { - Q.S. Al-Kafirun } \\
\text { - Q.S. Yunus: 40-41 } \\
\text { - Q.S. Al Kahfi: } 29\end{array}$ & $\begin{array}{l}\text { - Mengidentifikasi perilaku } \\
\text { bertoleransi sesuai dengan Al- } \\
\text { Qur'an surat Al Kafirun, Yunus: } \\
\text { 40-41 dan Al Kahfi: 29. } \\
\text { - Mempraktikkan perilaku } \\
\text { bertoleransi sesuai dengan Al- } \\
\text { Qur'an surat Al Kafirun, Yunus : } \\
\text { 40-41 dan Al Kahfi : 29. } \\
\text { - Menunjukkan perilaku } \\
\text { bertoleransi sesuai dengan Al- } \\
\text { Qur'an surat Al Kafirun, Yunus : } \\
\text { 40-41 dan Al Kahfi : 29. }\end{array}$ \\
\hline
\end{tabular}

Berdasarkan isi kurikulum, konsep moderasi Islam sudah terdapat dalam kurikulum PAI. Namun, dalam implemetasinya masih belum semaksimal, padahal kalau kita konsep moderasi Islam ini dapat menumbuhkembangkan sikap toleran dan inklusif. Namun Pendidikan Agama Islam yang hanya menekankan kebenaran agamanya sendiri dan ketidak-benaran agama lain. Konsepsi pemahaman yang biner seperti iman kafir, muslim non muslim, dan baik benar. Yang sangat berpengaruh terhadap cara pandang siswa terhadap agama lain misalnya mau tidak mau harus 'dibongkar ulang'. Agar sekelompok penganut agama tidak lagi memandang agama lain. Sebagai agama yang 'salah' dan tidak ada jalan keselamatan kecuali dalam agama yang diyakininya. 
Kegagalan dalam menumbuh kembangkan sikap toleran dan inklusif dalam pendidikan agama. Hanya akan melahirkan sayap radikal dalam beragama. Meminjam filsafat pendidikan Paulo Freire Sudah saatnya pendidikan agama diarahkan pada arena pembebasan dari belenggu doktrin-doktrin agama yang eksklusif dan intoleran. Menuju formulasi pendidikan agama yang inklusif (Freire, 2007).

Pendidikan harus diarahkan untuk proses kemerdekaan, bukan menjinakkan budaya yang serba eksklusif. Sebab cara pandang atau pemahaman teologis yang ekslusif dan intoleran yang demikian. Pada gilirannya akan dapat merusak harmonisasi agama-agama dan menghilangkan sikap untuk saling menghargai kebenaran dari agama lain. Di sinilah sikap moderat menuai relevansinya, sehingga sikap seseorang akan lebih inklusif, toleran dan humanis sebagaimana menjadi karakter yang dimiliki orang-orang moderat (Burhani, 2012).

Menurut Azyumardi Azra, untuk membangun hubungan yang harmonis antar umat beragama dan menciptakan suasana inklusif dalam beragama. Maka dibutuhkan kemampuan dari setiap kelompok keagamaan. Untuk mendalami pemahaman mutual atas doktrin-doktrin dan praktik-praktik kelompok keagamaan lain sebagai prioritas pertama (Azra, 2007). Hal ini dilakukan sebagai pendalaman terhadap pengenalan kemajemukan terhadap aspek tafsir ajaran keagamaan. Posisi pemahaman mutual ini bagi penulis memungkinan terciptanya pemahaman keagamaan yang inkslusif. Pendidikan agama sejatinya harus membangun visi pendidikan yang mengembangan aspek tersebut di atas.

Akhirnya, di masa depan perlu ada rekonstruksi pendidikan agama secara umum, dan terlebih pendidikan Islam secara khusus. Rekonstruksi ini harus di mulai dari upaya pembaruan pemikiran keagamaan. Landasan utama pembaruan pemikiran keagamaan bagi penulis tentu berada pada domain sistem pendidikan agama. Pendidikan agama menjadi penting untuk segera diformulasi ulang visi pengajarannya, Nilai-nilai Tawassut (Moderat), Tasamuh (Toleransi), Tawazun (Balance), Wathoniyah Wa Muwathonah (Materi Kebangsaan). Karena siswa membutuhkan semangat beragama yang inklusif. Beragama yang tidak hanya mengedepankan emosi keagamaan yang "fanatik-buta". Tetapi lebih pada penguatan semangat keagamaan yang inklusif dan pluralis. Siswa juga harus diarahkan untuk menegakkan nilai kemanusian yang menghargai kemajemukan. 
Kata moderat dalam bahasa Arab dikenal dengan alwasathiyah. Dalam Alquran merupakan kata yang terekam dari QS. Al-Baqarah: 143. Kata al-Wasath dalam ayat tersebut bermakna terbaik dan paling sempurna. Dalam hadis yang sangat populer juga disebutkan bahwa sebaik-baik persoalan adalah yang berada di tengah-tengah. Dalam artian dalam melihat dan menyelesaikan satu persoalan, Islam moderat mencoba melakukan pendekatan kompromi dan berada di tengah-tengah, begitupula dalam menyikapi sebuah perbedaan, baik perbedaan agama ataupun mazhab, Islam moderat selalu mengedepankan sikap toleransi, saling menghargai, dengan tetap meyakini kebenaran keyakinan masing-masing agama dan mazhab. Sehingga semua dapat menerima keputusan dengan kepala dingin, tanpa harus terlibat dalam aksi yang anarkis.

Moderat dalam arti al-wasat sebagai model berfikir dan berinteraksi secara seimbang di antara dua kondisi, sehingga sesuai dengan prinsip-prinsip Islam dalam berakidah, beribadah dan beretika setidaknya bisa dilihat kesesuaiannya dengan pertimbangan-pertimbangan dalam berperilaku dalam etika Islam yang senantiasa mengacu pada maqasid al-syari'ah dan memperhatikan ummahat al-fadail (Hanafi, 2013). Moderasi adalah ajaran inti agama Islam. Islam moderat adalah paham keagamaan yang sangat relevan dalam konteks keberagaman dalam segala aspek, baik agama, adat istiadat, suku dan bangsa itu sendiri. Tak pelak lagi, ragam pemahaman keagamaan adalah sebuah fakta sejarah dalam Islam. Keragaman tersebut, salah satunya, disebabkan oleh dialektika antara teks dan realitas itu sendiri, dan cara pandang terhadap posisi akal dan wahyu dalam menyelesaikan satu masalah. Konsekuensi logis dari kenyataan tersebut adalah munculnya terma-terma yang mengikut di belakang kata Islam. Sebut misalanya, Islam Fundamental, Islam Liberal, Islam Progresif, Islam Moderat, dan masih banyak label yang lain.

Islam pada dasarnya adalah agama universal, tidak terkotak-kotak oleh label tertentu, hanya saja, cara pemahaman terhadap agama Islam. Diterima atau tidak, itulah fakta yang ada dewasa ini yang mempunyai akar sejarah yang kuat dalam khazanah Islam. Fakta sejarah menyatakan bahwa embrio keberagamaan tersebut sudah ada sejak era Rasulullah, yang kemudian semakin berkembang pada era sahabat, terlebih khusus pada era Umar bin Khattab. Ia kerap kali berbeda pandangan dengan sahabat-sahabat yang lain, bahkan mengeluarkan ijtihad yang secara sepintas bertentangan dengan keputusan hukum yang ditetapkan oleh Rasululullah SAW sendiri. 
Berdasarkan pengertian di atas ajaran Islam yang universal dan bercorak seimbang, maka al-wasathiyyah didefinisikan sebagai sebuah metode berpikir, berinteraksi dan berperilaku yang didasari atas sikap tawazun (seimbang) dalam menyikapi dua keadaan perilaku yang dimungkinkan untuk dibandingkan dan dianalisis, sehingga dapat ditemukan sikap yang sesuai dengan kondisi dan tidak bertentangan dengan prinsip-prinsip ajaran agama dan tradisi masyarakat. Secara lebih jelas bentuk moderasi Islam dapat dilihat dari aktualisasinya dalam mengatur tiga ruang di atas, yaitu tadbir al-nafs, tadbir al-manzil, dan tadbir al-mudun (Yahya, 2018).

Pertama, tadbir al-nafs. Dalam hal ini seyogyanya seseorang harus mampu berfikir dan bertindak sesuai dengan maqasid al-syari'ah dan berdasarkan pertimbangan ummahat al-fadail. Misalnya sikap seseorang dalam menyikapi umat agama lain. Seharusnya klaim kebenaran (truth claim) dalam keyakinan agama tidak perlu untuk diperdebatkan bahkan cenderung dipaksakan untuk diyakini orang yang berbeda agama. Hal ini malah akan mengganggu harmonisasi dalam kehidupan beragama sehingga memantik adanya konflik-konflik horizontal. Tindakan ini sesuai dengan tujuan syariat karena menjaga kepentingan primer (al-daruriyyat) manusia dalam menjaga keyakinannya (hifz al-din) dan juga tindakan ini menunjukkan kebijaksanaan (alhikmah) seseorang karena mampu menahan kehendaknya untuk tidak memaksa orang lain membenarkan keyakinannya (Burhani, 2012).

Kedua, tadbir al-manzil. Maksud dari manzil disini tidak hanya sebatas lingkup keluarga, tetapi mencakup juga organisasi maupun institusi yang di dalamnya terdapat kumpulan orang-orang yang mempunyai kepentingan bersama. Contoh dari aplikasi etika Islam dalam lingkup ini adalah pembagian harta warisan dalam keluarga. Dalam penentuan pembagian warisan di Indonesia boleh memilih antara tiga cara, berdasarkan hukum agama, perdata atau hukum adat. Adanya beberapa pilihan ini karena mempertimbangkan kondisi sosial yang ada di Indonesia. Misalnya penerimaan hokum adat ini berdasarkan tradisi ('urf) yang sudah ada di masyarakat yang sudah menjadi sebuah keniscayaan. Egalitarianisme Islam memandang semua masyarakat adalah sama di hadapan Allah, sehingga semua adat yang ada di masyarakat bisa menjadi sumber hukum, tidak hanya adat yang ada di masyarakat Arab. Semua adat ( 'urf) selama tidak bertentangan dengan prinsip ajaran Islam maka dalam batas-batas tertentu bisa diterima sebagai hukum Islam (Fuad, 2016). Hal ini jelas selaras dengan maksud dari tujuan 
syariah yaitu menjaga hak kepemilikan harta (hifz al-mal) dan juga prinsip keadilan (al'adalah) dalam mempertimbangkan pandangan akal dan wahyu.

Sikap yang demikian ini jelas selaras dengan karakteristik Islam moderat. Menurut Abou Fadl, Islam moderat memandang hukum abadi Tuhan yang ada di dalam Al-Qur'an diturunkan secara spesifik terhadap persoalan tertentu berdasarkan persoalanpersoalan umat yang ada di zaman Nabi, sehingga putusan spesifik ini harus dipahami secara konteks. Putusan spesifik ini bukanlah tujuan itu sendiri, melainkan tujuan itu untuk mencapai tujuan moral dari Al-Qur'an seperti keadilan, keseimbangan, kasih sayang, kesetaraan, kebajikan dan lain-lain (Fadl, 2005).

Dengan demikian maka pesan etis di dalam Al-Qur'an menjadi pertimbangan dalam memutuskan sebuah hukum dengan mempertimbangkan kondisi sosiohistorisnya. Cara ini merupakan corak Islam di nusantara yang memang harus diperkuat sehingga nilai-nilai moderasi ini tetap terjaga. Bahkan Baso melihat manuskripmanuskrip nusantara abad 15, misalnya undang-undang Malaka, ternyata di dalamnya menyebutkan bahwa ketika itu masyarakat Nusantara menyepakati adanya empat hukum: Hukum Syara', Hukum Akal, Hukum Fa'al, dan Hukum Adat (Baso, 2015). Realitas inilah yang seharusnya menjadi perhatian sekelompok orang yang ingin memaksakan penerapan hukum agama secara radikal, sehingga bisa lebih etis dalam mengambil sikap dengan melihat heterogenitas masyarakat Indonesia.

Ketiga, ruang aktualisasi etika adalah tadbir al-mudun. Tujuan akhir dari etika politik adalah terwujudnya kondisi masyarakat yang hidup aman, tentram, damai dalam sebuah Negara (al-daulah). Contoh dari penerapan etika Islam dalam hal ini adalah menjaga keutuhan dan stabilitas sebuah Negara meskipun bukan berbentuk Negara Islam. Kondisi ini sebagaimana yang terjadi di Indonesia, sebagai warga Negara seharusnya senantiasa proaktif dalam mempertahankan NKRI sebagai wujud final Negara bagi bangsa Indonesia. Dalam hal ini kiai Sahal menggolongkan etika berpolitik ke dalam peran politik tingkat tinggi (high politics) (Sahal \& Aziz, 2015) yang terdiri dari: politik kebangsaan, kerakyatan dan etika berpolitik. Politik kebangsaan berarti konsisten dalam menjaga keutuhan NKRI. Politik kerakyatan berarti aktif memberikan penyadaran tentang hak-hak dan kewajiban rakyat serta melindungi mereka dari tindakan yang tidak berpihak kepada mereka. Sedangkan etika politik berarti 
menanamkan kesadaran kepada masyarakat agar tercipta kehidupan politik yang santun dan bermoral sehingga tidak menghalalkan segala cara.

\section{SIMPULAN DAN SARAN}

Berdasarkan perkembangannya, dunia Pendidikan tidak bisa mengelak dari hukum dinamika kehidupan dengan latar masyarakat multikultural. Sejumlah lembaga tertentu mencoba mengembangkan kurikulumnya dengan memasukkan, atau bahkan mengadopsi seluruhnya kurikulum Pendidikan Nasional. Kurikulum tak lain merupakan seperangkat materi pendidikan dan pengajaran yang diberikan kepada peserta didik, atau sebuah program yang di bawah bimbingan dan tanggung jawab lembaga pendidikan tertentu.

SMA/SMU merupakan Lembaga Pendidikan yang peserta didik bukan hanya peserta didik Islam, tetapi juga terdapat banyak juga peserta didik Kristen, Hindu, bahkan Budha. Tentu menjadi problem ketika kita menganggap agama Islam, paling benar. Melihat kenyataan di atas maka perlu kiranya mewujudkan pendidikan Islam yang bersifat wasathiyah atau moderat sesuai dengan lajunya zaman. maka Pendidikan Islam, khususnya di Indonesia sudah seharusnya mengacu pada konsep wasathiyah (moderat). Hal ini untuk mengantisipasi adanya kekacauan yang semakin marak. Yang menimbulkan pemikiran yang sifatnya asal-asalan saja. Tanpa ada landasan yang shohih, dalam arti al-Qur'an dan sunnah.

Tawaran model pendidikan agama di SMA biasa dilakukan dengan merekonstruksi atau mengembangkan kurikulum dengan pendekatan bidang studi dan rekonstruksionisme. Dari pengajaran Nilai-nilai Moderasi Islam dalam pembelajaran PAI yang mendalam tersebut diharapkan lulusan pesantren mampu menangkap sisi-sisi moderasi yang ada di dalamnya sehingga menjadi sosok yang berwawasan moderat yang mempunyai karakter humanis, toleran, inklusif sesuai dengan wajah Islam Indonesia yang rahmat lil 'alamin. 


\section{DAFTAR PUSTAKA}

Abdurrohman, A. (2017). Eksistensi Islam Moderat dalam Perspektif Islam. Jurnal Pendidikan Agama Islam, 2(2), 121-138.

Achmad, N. (2001). Pluralitas Agama: Kerukunan dalam Keragaman. Jakarta: Kompas.

Ainiyah, N. (2013). Pembentukan Karakter Melalui Pendidikan Agama Islam. Jurnal Al-Ulum, 13(1), 25-38.

Anwar, S. (2016). Implementasi Pendidikan Nilai dalam Pembentukan Karakter Peserta Didik. Bandar Lampung: Pusat Penelitian dan Penerbitan Lembaga Penelitian dan Pengabdian Kepada Masyarakat IAIN Raden Intan Lampung.

Arif, M. (2012). Pendidikan Agama Islam Inklusif- Multikultural. Jurnal Pendidikan Islam, 1(1), 1-18.

Aziz, A. (2016). Menangkal Islamofobia melalui Re-Interpretasi Al-Qur'an. Al-A'raf, XIII(1), 65-82.

Azizah, A., Muslihudin, \& Suteja. (2013). Orientasi Pendidikan Karakter pada Mata Pelajaran Pendidikan Agama Islam (PAI) di Sekolah Menengah Atas (SMA) dalam Kurikulum 2013 Perspektif Thomas Lickona. Jurnal Al Tarbawi Al Haditsah, 1(2), 1-13.

Azra, A. (2007). "Eksplorasi atas Isu-Isu Kesetaraan dan Kemajemukan: Hubungan antar Agama” dalam Franz Magnis Suseno dkk. Memahami Hubungan antar Agama. Yogyakarta: eLSAQ Press.

Baidhawy, Z. (2005). Pendidikan Agama Berwawasan Multikultural. Jakarta: Erlangga.

Baso, A. (2015). Islam Nusantara: Ijtihad Jenius dan Ijma' Ulama Nusantara (Jilid 1). Jakarta: Pustaka Afid.

Burhani, A. N. (2012). Al-Tawwasut wa-I I'tidal: The NU and Moderatism In Indonesian Islam. Asian Journal of Social Science, 40(5/6), 564-581.

Fadl, K. A. El. (2005). Selamatkan Islam dari Muslim Puritan (terj. Helm). Jakarta: Serambi Ilmu Semesta.

Freire, P. (2007). Politik Pendidikan: Kebudayaan, Kekuasaan, dan Pembebasan. Yogyakarta: Pustaka Pelajar.

Fuad, M. (2016). "Hukum Islam Indonesia: dari Nalar Partisipatoris Hingga Emansipatoris" dalam Akhmad Sahal dan Munawir Aziz (ed.), Islam Nusantara: dari Ushul Fiqh Hingga Paham Kebangsaan. Bandung: Mizan Pustaka.

Hair, M. A. (2018). Pendidikan Agama Islam dalam Keluarga dan Masyarakat. Ahsana Media: Jurnal Pemikiran, Pendidikan dan Penelitian Ke-Islaman, 4(2), $28-34$.

Hanafi, M. M. (2013). Moderasi Islam: Menangkal Radikalisasi Berbasis Agama. Jakarta: Ikatan Alumni Al-Azhar Mesir Cabang- Indonesia. 
Harahap, S. (1997). Islam Dinamis: Menegakkan Nilai-Nilai Ajaran Al-Qur`an dalam Kehidupan Modern di Indonesia. Yogyakarta: Tiara Wacana.

Kholil, M. (1994). Al-Qur`an dari Masa ke Masa. Solo: Rahmadani.

Kholiq, A. (2015). Pendidikan Agama Islam dalam Kebudayaan Masyarakat Kalang. Jurnal at-Taqaddum, 7(2), 327-345.

Listia, Arham, L., \& Gogali, L. (2007). Problematika Pendidikan Agama di Sekolah: Hasil Penelitian Tentang Pendidikan Agama di Kota Jogjakarta 2004-2006. Yogyakarta: Interfidei.

Majid, A. (2004). Pendidikan Agama Islam Berbasis Kompetensi: Konsep dan Implementasi Kurikulum 2004. Bandung: Remaja Rosdakarya.

Nata, A. (1996). Al-Qur'an dan Hadits: Dirasah Islamiyyah I (Cet. ke-V). Jakarta: Raja Grafndo Persada.

Rokhmad, A. (2012). Radikalisme Islam dan Upaya Deradikalisasi Paham Radikal. Walisongo, 20(1), 79-114.

Sahal, A., \& Aziz, M. (2015). Islam Nusantara: dari Ushul Fiqh Hingga Paham Kebangsaan. Bandung: Mizan Pustaka.

Shihab, M. Q. (1996). "Membumikan” Al-Quran: Fungsi dan Peran Wahyu dalam Kehidupan Masyarakat (Cet. ke-XI). Bandung: Mizan Pustaka.

Suharto, T. (2017). Indonesianisasi Islam: Penguatan Islam Moderat dalam Lembaga Pendidikan Islam Di Indonesia. Al-Tahrir, 17(1), 155-178.

Sulaiman, A.-H. S. K. M. (1989). Menyanggah Keraguan terhadap Al-Qur'an Bukti AlQur'an sebagai Wahyu. Solo: Ramadhani.

Wibowo, A. M. (2014). Internalisasi Nilai-Nilai Karakter Bangsa melalui Mata Pelajaran PAI pada SMA Eks RSBI di Pekalongan. Analisa, 21(2), 291-303.

Wiyani, N. A. (2012). Pendidikan Agama Islam Berbasis Anti Terorisme di SMA. Jurnal Pendidikan Islam, I(2), 65-83.

Yahya, F. A. (2018). Meneguhkan Visi Moderasi Dalam Bingkai Etika Islam: Relevansi dan Implikasi Edukatifnya. In Annual Conference for Muslim Scholars (pp. 466478). 